\title{
Metacarpal index in Marfan's syndrome and in constitutional tall stature
}

\author{
M Nelle, J Tröger, G Rupprath, M Bettendorf
}

\begin{abstract}
The metacarpal index (MCI) in 54 children with constitutional tall stature was mean (SD) $8.65(0.8)$ and in 55 with Marfan's syndrome $9 \cdot 15(0.9)$. Indices in both groups showed arachnodactyly and differed from those found in normal individuals $(<7 \cdot 9)$. Because the MCI is a poor discriminator patients with tall stature or clinical signs of arachnodactyly should be examined for additional signs of Marfan's syndrome or other hereditary disorders of connective tissue.
\end{abstract}

(Arch Dis Child 1994; 70: 149-150)

Marfan's syndrome is an autosomal inherited disorder of the connective tissue. Stigmata of Marfan's syndrome are associated with the skeleton, eyes, and cardiovascular system. ${ }^{1} \mathrm{~A}$ number of signs and tests have been described to help establish skeletal abnormalities in patients with this syndrome. Sinclair et al introduced the metacarpal index (MCI) based on the fact that bones of the extremities in patients with Marfan's syndrome tend to be longer and thinner than normal. ${ }^{2}$ The index represents the ratio of the mean length to the mean width of the second to fifth metacarpal bones, measured at their midpoints, visualised by radiography. In healthy individuals the index is less than 7.9. Arachnodactyly is defined as an index greater than $8 \cdot 5 .^{23}$ Typical features of arachnodactyly have been reported to occur in association with osteogenesis imperfecta, dystrophia myotonica, homocystinuria and Ehlers-Danlos syndrome, ${ }^{4}$ but no data exist in patiènts with constitutional tall stature.

University Children's Hospital of

Heidelberg, Germany, Department of Paediatrics

M Nelle

M Bettendorf

Department of Paediatric Radiology J Tröger

Municipal Children's Hospital, Kaiserslautern G Rupprath

Correspondence and reprint requests to: Dr Mathias requests to: Dr Mathias Nelle, Department of Paediatrics, University of Heidelberg, Im Neuenheimer Feld 150, D-69120 Heidelberg, Germany. Accepted 16 September 1993

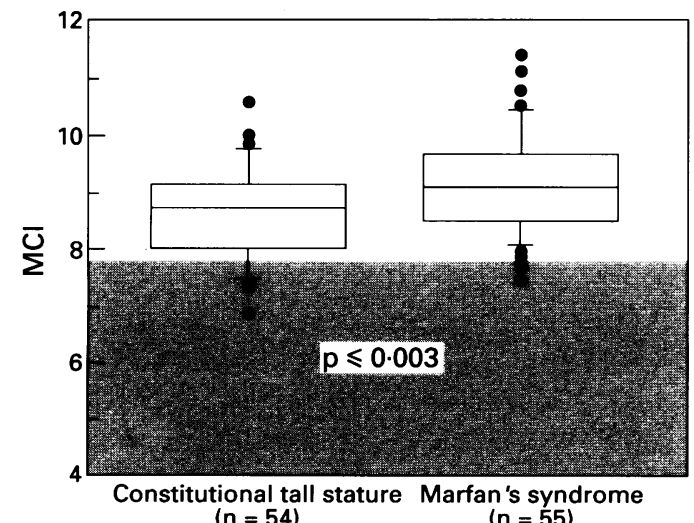

MCI in patients with constitutional tall stature and Marfan's syndrome. Box plots represent the 10th, 25th 50th, 75th, and 90th centiles of the MCI. Indices above the 90 th and below the 10th centiles are plotted separately. The hatched area indicates the MCI in normal individuals.
The aim of our study was to compare the MCI of children with Marfan's syndrome and constitutional tall stature and to find out whether this index discriminates between the two patient groups and verifies the clinical impression of arachnodactyly in children with constitutional tall stature.

\section{Patients and methods}

PATIENTS

Fifty four children ( 22 girls and 32 boys) with constitutional tall stature (age 13.5 (2.0) years; range $7 \cdot 3-16 \cdot 2)$ and 55 children (35 girls and 20 boys) with Marfan's syndrome (age 10.7 $(4 \cdot 0)$ years; range $2 \cdot 3-19 \cdot 7)$ were examined for radiographic signs of arachnodactyly.

\section{METHODS}

In a posterior-anterior radiograph of the left hand of all patients the MCI was evaluated as the ratio of the mean axial length of the second, third, fourth, and fifth metacarpals to the width of the same metacarpals at their midpoints. An index of greater than 8.5 was considered as abnormal and indicated arachnodactyly. ${ }^{3}$

A diagnosis of constitutional tall stature was established when the length of the children was above the $97 \%$ centile for age and other causes were ruled out. Patients with signs of other disorders (that is hyperthyroidism, chromosome aberration, dysmorphic syndromes) were excluded from the study.

Both groups were carefully examined for signs of Marfan's syndrome. The diagnostic work up in patients with suspected Marfan's syndrome inçluded clinical and anthropometrical examination, family history, one and two dimensional echocardiography, and slit lamp examination. ${ }^{1}$

\section{STATISTICAL ANALYSES}

Data are presented as mean SD. Statistical comparisons were made by unpaired $t$ test. Correlation coefficients $(r)$ were calculated using Stat View on a MacIntosh personal computer.

\section{Results}

The MCI in the group with constitutional tall stature was $8.65(0.8)$ (range 6.87-10.58) and in children with Marfan's syndrome $9 \cdot 15(0.9)$ (range 7.5-11.4), showing a significant difference $(p<0.003$; see figure). An index greater than 8.5 was found in $56 \%$ of patients with the 
Comparisons of mean (SD) MCI in patients with constitutional tall stature and Marfan's syndrome

\begin{tabular}{lll}
\hline & $\begin{array}{l}\text { Constitutional } \\
\text { tall stature } \\
(n=54)\end{array}$ & $\begin{array}{l}\text { Marfan's } \\
\text { syndrome } \\
(n=55)\end{array}$ \\
\hline Total & $8.65(0 \cdot 8)$ & $9 \cdot 15(0.9)^{\star}$ \\
Girls & $8.97(0 \cdot 7)$ & $9 \cdot 29(0.9)$ \\
Boys & $8.42(0.8)$ & $8.90(0.8)$ \\
\hline
\end{tabular}

${ }^{\star} \mathrm{p}<0.003$.

constitutional tall stature and in $79 \%$ of the patients with Marfan's syndrome. In patients with Marfan's syndrome the MCI tended to increase with age $(r=0.47)$, whereas the MCI of children with constitutional tall stature was age independent $(r=0.07)$.

Girls of both groups exhibited a higher MCI $(9 \cdot 17(0.8)$; range $7 \cdot 5-11.4)$ than boys $(8.61$ $(0 \cdot 8)$; range $6 \cdot 9-11 \cdot 1 ; \mathrm{p}<0 \cdot 001)$. Furthermore, in girls with constitutional tall stature the MCI (8.97 (0.7); range 7.75-10.6) was higher than in boys $(8.42(0.8)$, range 6.9-9.9; $\mathrm{p}<0.01$ ); in comparison the $\mathrm{MCI}$ in the group with Marfan's syndrome was not sex dependent (see table).

\section{Discussion}

Our study shows that the clinical impression of arachnodactyly in children with constitutional tall stature corresponds to a greater MCI. A significant difference of the indices between patients with Marfan's syndrome and those with constitutional tall stature was found, but indices in both groups were higher than normal.

Sinclair et al examined 20 adult patients with Marfan's syndrome and compared them with 100 healthy adults: they reported a greater MCI in those with Marfan's syndrome. ${ }^{2}$ However, the validity of the test was questioned by other authors. ${ }^{3}$ Joseph and Meadow first applied the MCI to children and found out that it can be used for diagnosis of arachnodactyly in children with Marfan's syndrome. ${ }^{5}$

A significantly higher MCI in girls compared with boys was found by Joseph and Meadow and Parish, ${ }^{56}$ presumably caused by earlier skeletal maturation in girls. In our study there was a significant difference between the MCI of boys and girls of both patient groups: this sex difference of the MCI was also observed in children with constitutional tall stature, but not in children with Marfan's syndrome. The MCI of girls with Marfan's syndrome correlates with chronological age; this correlation was not found in the other groups. However, it remains speculative as to whether earlier onset of pubertal development and skeletal maturation in girls contribute to a higher MCI. As we performed a retrospective study, the patient groups were not age and sex matched and no data on bone age and stage of sexual development were available for analysis. Future investigations have to focus on the relation of bone age rather than chronological age and stage of puberty to the MCI in order to establish age and sex dependency of the MCI. The diagnosis of Marfan's syndrome is complicated by phenotypic pleotrophy and variability resulting in clinical heterogeneity. Neither a clinical test nor a biochemical test is available to establish the diagnosis of Marfan's syndrome. Diagnosis and management has to consider the variable spectrum of cardiac, orthopaedic, and anthropometric aspects and requires positive findings in at least two of the four criteria. ${ }^{1}$ Arachnodactyly is only a minor sign of Marfan's syndrome. The radiographic examination does not improve the diagnostic management. Simple clinical manoeuvres such as the thumb sign or wrist $\operatorname{sign}^{4}$ are helpful to assess arachnodactyly.

This study supports the clinical observation that arachnodactyly is a common feature in patients with constitutional tall stature. Even though a significant difference in MCI of patients with Marfan's syndrome and constitutional tall stature was found, a considerable overlap exists, making the MCI a poor discriminator between these two patient groups.

Therefore, patients with tall stature and the clinical aspect of arachnodactyly should be carefully examined for signs of Marfan's syndrome or other hereditary disorders of the connective tissue.

1 Pyeritz RE, McKuisick VA. The Marfan syndrome: diagnosi and management. $N$ Engl F Med 1979; 300: 772-7.

2 Sinclair RJG, Kitchin AH, Turner RWD. The Marfan syndrome. $Q \mathcal{f}$ Med 1960; 29: 19-46.

3 Eldridge R. The metacarpal index: a useful aid in the diagnosis of the Marfan syndrome. Arch Intern Med 1964; 113. $140-6$.

4 Walker BA, Beighton PH, Murdoch JL. The Marfanoid hypermobility syndrome. Ann Intern Med 1969; 71: 349-52.

5 Joseph MC, Meadow SR. The metacarpal index of infants. Arch Dis Child 1969; 44: 515-6.

6 Parish JG. Radiographic measurements of the skeletal structure of the normal hand. $B r \mathcal{F}$ Radiol 1966; 39: 52 . 